\title{
FUNCTIONAL AND AESTHETIC EFFECTS OF SPREADER GRAFTS TECHNIQUE IN RHINOPLASTY
}

\author{
Daniel Yankov \\ Division of Burn, Plastic, Reconstructive and Aesthetic Surgery, Department of Surgery, \\ Naval Hospital of Varna, Military Medical Academy of Sofia
}

\begin{abstract}
PURPOSE: The spreader grafts technique is recognised and widely employed in rhinoplasty for middle nasal vault reconstruction. The purpose of this study is to describe this method and analyse the functional and aesthetic effects of its application.

MATERIAL AND METHODS: Autologous or alloplastic sticks with individually designed measurements were submucoperichondrially implanted between the frontmost parts of anterior septal edge and upper lateral cartilages. This technique was applied in $\mathbf{3 6}$ patients with different indications for middle nasal vault reconstruction. Of them, 26 underwent primary and 10-secondary rhinoplasties. Open approach was used in 32 patients but endonasal one in the rest four patients only.

RESULTS: We present our recent clinical material when using the spreader grafts technique. These grafts help to achieve harmonious dorsal aesthetic lines, internal nasal valve competence preservation or recreation, and maintenance of the straightened position of the corrected deviated cartilaginous septal dorsum.

CONCLUSION: Though the spreader grafts technique is the solution of choice in many cases, particularly in secondary rhinoplasties, it is neither universal, nor perfect. There is uninterrupted debate on its true value in nasal patency. The result depends considerably on the surgeon's technical skills and precision. Based on the literature available and our own experience, we could conclude that the spreader grafts technique in rhinoplasty presents with both positive and negative patterns.
\end{abstract}

Keywords: rhinoplasty, spreader grafts, middle nasal vault, nasal dorsum aesthetics, nasal valve reconstruction, deviated septal dorsum

\footnotetext{
Address for correspondence:

Daniel Yankov, MD, PhD

Division of Burn, Plastic, Reconstructive and Aesthetic

Surgery

Department of Surgery, Naval Hospital of Varna

Military Medical Academy of Sofia,

3 Hristo Smirnenski Str.,

9010 Varna, Bulgaria

E-mail:yankovplastics@yahoo.com
}

Received: February 10, 2014

Accepted: December 11, 2013 


\section{INTRODUCTION}

Since the invention and introduction of spreader grafts in 1980's by Sheen (15), the technique has gained huge popularity. Principally, the grafts were used to act as volumetric expanders to stabilise and push the upper lateral cartilages (ULC's) away from the dorsal septum to increase the internal nasal valve angle (17). The spreader grafts are indicated both in cases of primary and secondary rhinoplasty. Following the composite reduction of the nasal hump, spreader grafts are usually positioned to prevent the complication of nasal valve collapse. During component hump reduction, this technique should always have to be in consideration as a complement to ULC spreader flaps, particularly in patients with short nasal bones and flaccid ULCs. The autospreader cartilage sticks successfully correct the abnormal narrowing of the middle vault in patients suffering from postoperatively manifested inverted ' $\mathrm{V}$ ' deformity. After the septal work, when the deviation has been corrected by scoring or by resection thus leaving ' $\mathrm{L}$ shaped frame, spreader grafts are inserted between the ULC's and the dorsal part of septal cartilage for structural reinforcement and straightening of the cartilaginous crooked nose (8). Herewith we are going to attract the readers attention to the main characteristics and some important details of the technique, refracted by the prism of our own experience.

\section{MATERIAL AND METHODS}

Autologous or alloplastic sticks with individually designed measurements were submucoperichondrially implanted between the frontmost parts of anterior septal edge and upper lateral cartilages. We applied this technique in 36 patients with different indications for middle nasal vault reconstruction. Of them, 26 underwent primary and 10 - secondary rhinoplasties. Open approach was used in 32 patients but endonasal one in the remaining four patients only. Septal cartilage was a donor site of choice for 33 patients while auricular concha cartilage was taken in 3 secondary cases after previously harvested quandrangular cartilage. Paired symmetrical grafts were transplanted in 27 patients, paired asymmetrical - in 7, and a single unilateral graft - in two patients. We combined spreader grafts with ULC's spreader flaps in the course of component hump re- duction in 7 primary cases, mainly to achieve effective increase of the internal nasal valve angle. In 13 cases, we additionally supported the structure of dorsal part of 'L'-shaped frame after septoplasty.

\section{Surgical technique}

In accordance with the original technique of Sheen, the spreader grafts are usually harvested from septal cartilage and shaped in rectangular bars, approximately $2-3 \mathrm{~cm}$ long, $3-5 \mathrm{~mm}$ wide, and $1,5 \mathrm{~mm}$ thick (Fig. 1). Auricular conchal cartilage can also be used for spreader grafts (9), especially in revision rhinoplasty with inadequate septal cartilage or due to surgeon's preference. The grafts are applicable either through open, or by endonasal approaches.

In our practice, we use both septal and auricular cartilages, but the former one is more reliable, being firmer and easier to modelling and fixing by sutures. The first step in the technique is the careful dissection of the mucoperichondrium from the osseocartilaginous nasal vault. We normally perform this maneuver by sharp aspirating cannula (Fig. 2), after hyperinfiltration with vasoconstrictive solution. If the intervention has been planned to correct solely the functional impairment of the nasal valve, no further dissection is needed (Fig. 3). In the course of composite or component hump reduction, the skin and dorsal soft tissues should also be elevated. Thus complete exposure of the lower and upper lateral cartilages, upper part of septal cartilage and nasal bones is created. In component reduction technique the ULC's are separated from the septal cartilage and the excess nasal bones are removed in order to open the nasal roof. At that stage, before going further with the grafts technique, we usually perform medial oblique osteotomies.

The next step of the nasal dorsum reconstruction by spreader grafts includes positioning of the harvested cartilages between the ULC's and the upper part of septal cartilage on both sides (Fig. 4). The grafts should extend cranially to cover the keystone area under the nasal bones. A single graft may be placed on one side if indicated, or asymmetrical grafts would have contributed to compensate a disproportional middle vault anatomy.

In limited internal valve functional rhinoplasty, we are very careful to create proportionally ade- 
Functional and aesthetic effects of spreader grafts technique in rhinoplasty

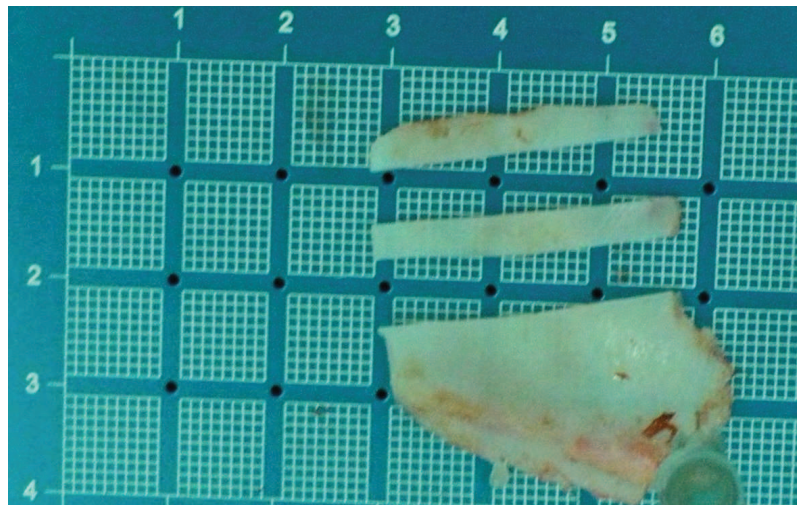

Fig. 1. Spreader grafts cut off from septal cartilage

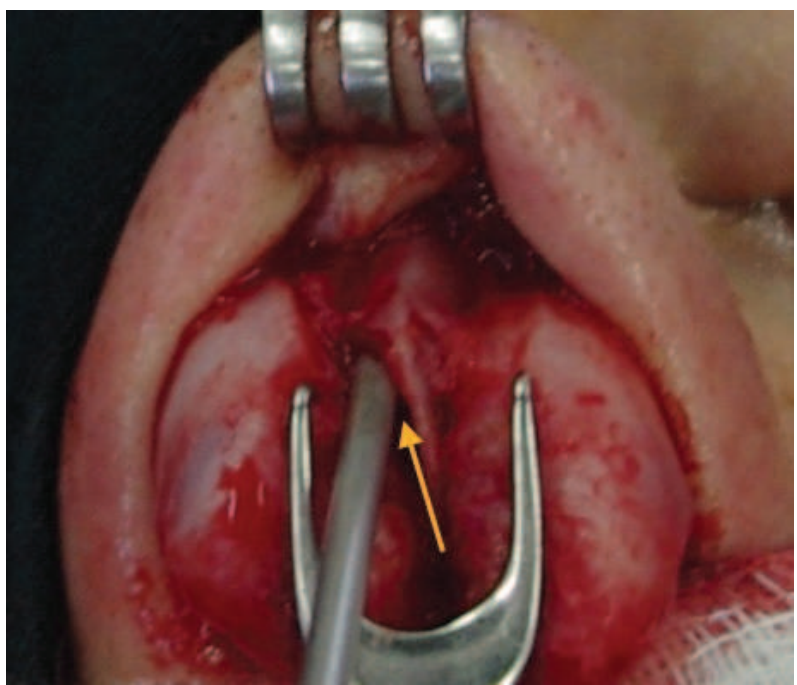

Fig. 2. Right side middle nasal vault submucosal tunnel

quate to the grafts measurements and volume submucosal tunnels. In this way, the grafts can be immobilised by the help of only one suture to the septum, at the entrance of the tunnels. In any other indications, no matter through open or closed approach, we fix the spreader grafts to the septal edge at least twice - adjacent to the keystone area cranially and at the anterior septal angle caudally. We fix the grafts with 5-0 polydioxanone sutures. Then the cartilage vault reconstruction could go on in different ways, in accordance with the patient's needs. In composite hump resection, inverted ' $\mathrm{V}$ ' deformity correction and in most cases of component reduction but weak ULC's, the reconstruction is accomplished by two or

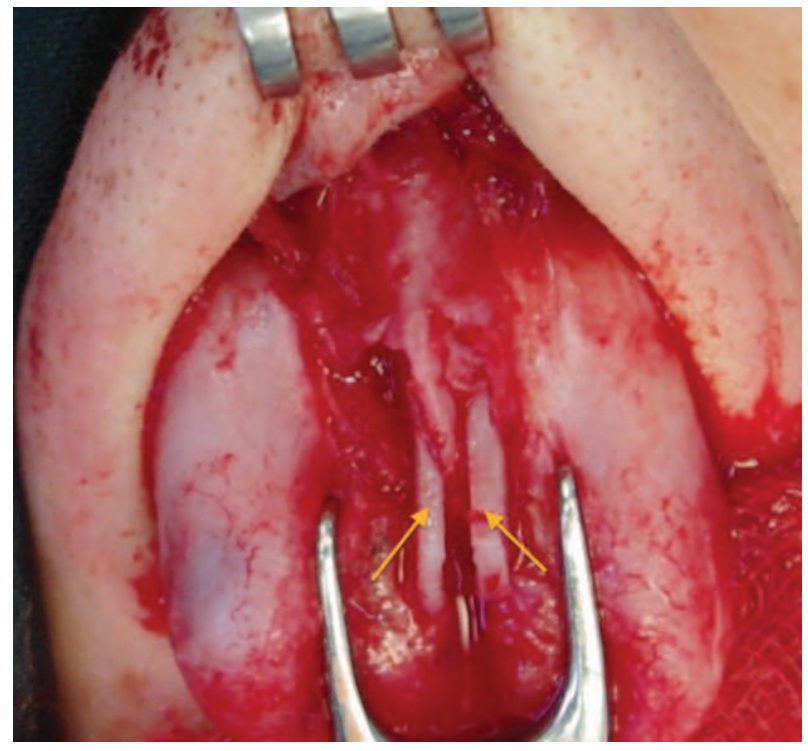

Fig. 3. Spreader grafts technique in not detached ULC's

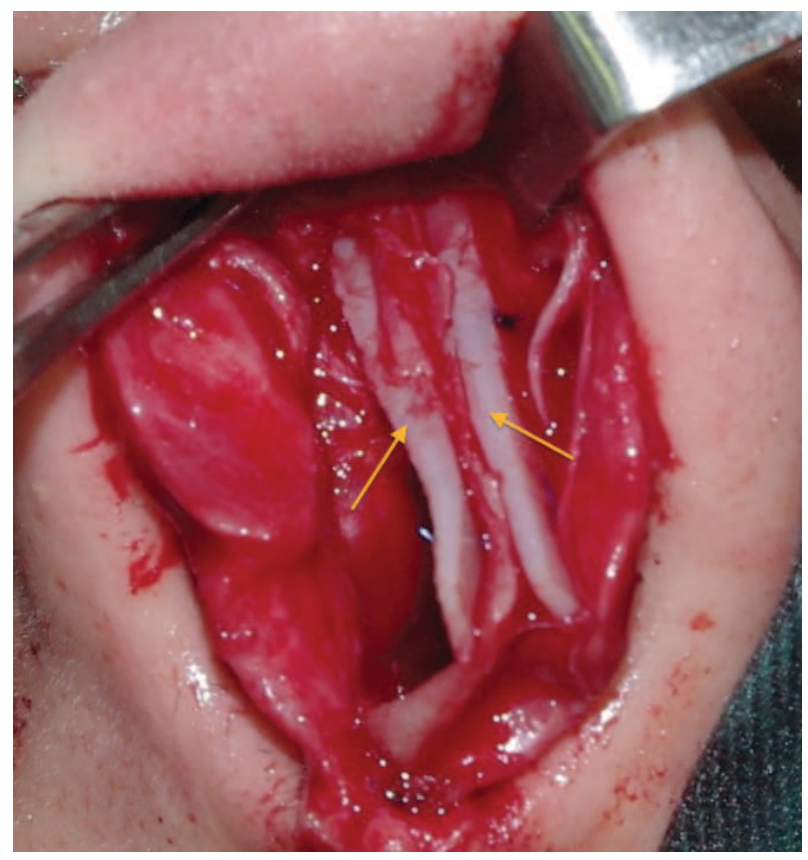

Fig. 4. Spreader grafts fixed to the anterior septal edge in detached ULC's 
three total mattress sutures between ULC's, grafts and dorsal septum.

Septal cartilage spreader grafts are highly recommended if structural support of the dorsal part of 'L'-shaped septal frame must be ensured (Fig. 5). In particular cases, spreader grafts can also be combined with spreader flaps in individually designed relationships. Precise covering of all cartilages by well-vascularised mucosa and soft tissues is crucial to grafts survival.

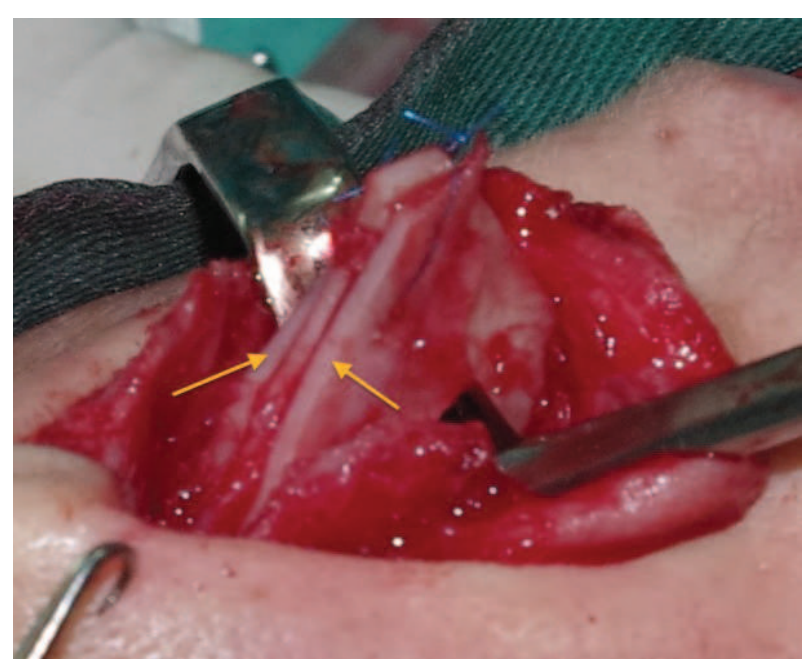

Fig. 5. Spreader grafts fixed to 'L'-shaped septal frame to correct deviation

\section{RESULTS}

The spreader grafts enabled the achieving harmonious dorsal aesthetic lines, internal nasal valve competence preservation or recreation, and maintenance of the straightened position of the corrected deviated cartilaginous septal dorsum.

Our results demonstrated that all but two patients were satisfied with the postoperative nasal function. From aesthetic point of view, there were certain prominent irregularities in the area of middle nasal vault in three patients. In two of them, they were due to spreader grafts incorrect fixation, and in the third one - to the whole lateral nasal wall displacement owing to poor splint immobilisation after lateral osteotomies.

\section{DISCUSSION}

Our postoperative results with the technique of spreader grafts are encouraging. We applied the method in a series of patients with diverse rhinoplasty problems. Some of them presented with severe postoperative nasal deformities and severe psychological trauma as well. The fact that the vast majority of these patients are satisfied with the achieved nasal functional activity and aesthetic appearance makes us feel confident in the effectiveness of this method. Although we recently prefer ULC's spreader flaps for cartilage vault reconstruction in primary aesthetic reductive rhinoplasty, in every patient of ours, the decision to use spreader grafts is obligatorily based on the safety and reliability of this technique when indicated.

The successful rhinoplasty is characterised by aesthetical improvement of the nasal-facial relationship, airflow passage and nasal valve patency preservation or restoration. Besides, individual patient's quality of life improves (19). Application of spreader grafts positively influences each of the above mentioned components of the desired result $(4,7,14)$. In spite of the positive results achieved, however, the surgical technique is not ideal and pluripotent. The extent of ULC lateralization from the septum by the spreader graft depends on the graft thickness. The thicker the graft is, the wider the nose becomes. Therefore, a discrepancy between the functional correction and aesthetical proportions of the dorsum may occur. Additionally, in patients suffering from ULC's weakness, spreader graft is limited in its ability to adequately support and lateralise the lateral nasal wall, hence reducing its functional outcome $(1,2,4,7)$.

Another drawback of spreader grafts technique is the need for sufficiently long cartilage grafts, which sometimes is difficult to harvest from the septal cartilage. In cases of overresected nasal dorsum in secondary rhinoplasty or after septoplasty, it is not always possible to obtain sufficient cartilage material from the septum. Alternative donor sites should come into consideration. The potential of ULC's flaps as a substitute of spreader grafts has been described $(3,5,12)$. This autospreader flap is a technique in which the free frontal ULC parts are folded 
on themselves and fixed to the anterior septal border while reducing the profile of the dorsum. The technique avoids the prolonged operative time and surgeon's efforts to harvest and carve cartilage for grafting from other locations (5). Spreader cartilage flaps are not effective, however, in cases of deviated dorsal septum and asymmetric dorsal aesthetic lines.

As for many other rhinoplasty problems, there are further alternatives for treatment of nasal valve collapse. Alar batten grafts are described as a useful tool for addressing nasal valve insufficiency owing to weak ULC's (2). Adequate lateralisation of lateral nasal walls can be achieved by the insertion of alar batten grafts into a precise pocket to the site of maximal ULC's collapse $(2,18)$. Both septal or auricular cartilage can be used. The convex surface of the cartilage must be oriented laterally to allow for maximal effect of pushing aside the collapsed portion of the lateral nasal wall. Alar batten graft helps also to resist the negative inspiratory forces that cause the collapse of the lateral nasal wall.

A H-graft has been recently described to contribute for internal nasal valve reconstruction with the benefit of an improved stability of the graft on septal dorsum, as well as presenting with the combined advantages of spreader and splay effects (16). This technique compensates the limitations of spreader grafts by providing lateral nasal wall lateralisation.

Though the preferable source for spreader grafts work-out is the autologous cartilage tissue, there exists a number of alloplastic materials already validated to the same purpose. Materials which have been used as spreader grafts are hyaluronic acid (Restylane $e^{\oplus}$ (10), calcium hydroxylapatite (Radiesse $\left.{ }^{\oplus}\right)$ (11), high-density porous polyethylene (Medpor ${ }^{\circledR}$ ) $(6,13)$, and polymer of polylactic and polyglycolic acid (Lactosorb ${ }^{\circ}$ ) (10). The technique of injection of calcium hydroxyapatite and hyaluronic acid was described by Nyte $(10,11)$. This procedure aimed at increasing the internal nasal valve angle and maintaining the nasal inspiration. The synthetic materials can be useful in revision surgeries, where inadequate donor cartilage frequently exists $(5,6)$. We haven't used alloplastic materials for spreader grafts managing being convinced of the advantages of the autogenous cartilage transplantation.

\section{CONCLUSION}

The spreader grafts technique is an important surgical instrument in rhinoplasty. The grafts serve to create aesthetic dorsal lines, proportionally wide middle nasal vault and straight dorsal septum in addition to septoplasty. They play a valuable role in the preservation and restoration of the normal internal nasal valve angle and support the structural stability of the cartilage vault. As, recently, both component dorsal reduction and consequent ULC's spreader flap reconstruction are widely applied, there is less need to use spreader grafts in rhinoplasty. Yet the method may happen to be the safe procedure of choice in specific primary or secondary nasal pathology.

\section{REFERENCES}

1. Andre, R. F., S. H. Paun, H. D. Vuyk. Endonasal spreader graft placement as treatment for internal nasal valve insufficiency: no need to divide the upper lateral cartilage from the septum. Arch. Facial Plast. Surg. 2004; 6(1): 240-243.

2. Becker, D. G., S. S. Becker. Treatment of nasal obstruction from nasal valve collapse with alar batten grafts. J. Long Term EV Med. Implants, 2003;13(3): 259-269.

3. Byrd, H. S., R. A. Meade, D. L. Gonyon. Using the autospreader flap in primary rhinoplasty. Plast. Reconstr. Surg., 2007;119(6): 1897-1902.

4. Faris, C., E. Koury, P. Kothari, A. Frosh. Functional rhinoplasty with batten and spreader grafts for correction of internal nasal valve incompetence. Rhinology, 2006;44(2): 114-117.

5. Gruber, R. P., E. Park, J. Newman, L. Berkowitz, R. Oneal. The spreader flap in primary rhinoplasty. Plast. Reconstr. Surg., 2007;119(6): 1903-1910.

6. Gürlek, A., M. Celik, A. Fariz, A. Ersöz-Oztürk, A. T. Eren, G. Tenekeci. The use of high-density porous polyethylene as a custom-made nasal spreader graft. Aesthet. Plast. Surg., 2006;30(1): 414-416.

7. Ingels, K. J., K. S. Orhan, N. van Heerbeek. The effect of spreader grafts on nasal dorsal width in patients with nasal valve insufficiency. Arch. Facial Plast. Surg., 2008;10(5): 354-356.

8. Mendelsohn, M. Straightening the crooked middle third of the nose: using porous polyethylene extended spreader grafts. Arch. Facial Plast. Surg., 2005;7(2): 74-80. 
9. Murrell, G. L. Auricular cartilage grafts and nasal surgery. Laryngoscope, 2004;114(12): 2092-2102.

10. Nyte, C. P. Hyaluronic acid spreader-graft injection for internal nasal valve collapse. Ear Nose Throat J., 2007;86(5): 272-273.

11. Nyte, C. P. Spreader graft injection with calcium hydroxylapatite: a nonsurgical technique for internal nasal valve collapse. Laryngoscope, 2006;116(7): 1291-1292.

12. Oneal, R. M., R. L. Berkowitz. Upper lateral cartilage spreader flaps in rhinoplasty. Aesthet. Surg. J., 1998;18(5): 370-371.

13. Reiffel, A. J., K. J. Cross, H. M. Spinelli. Nasal spreader grafts: a comparison of Medpor to autologous tissue reconstruction. Ann. Plast. Surg., 2011;66(1): 24-28.

14. Rhee, J. S., J. M. Arganbright, B. J. McMullin, M. Hannley. Evidence supporting functional rhinoplasty or nasal valve repair: a 25-year systematic review. Otolaryngol. Head Neck Surg., 2008;139(1): 10-20.

15. Sheen, J. H. Spreader graft: a method of reconstructing the roof of the middle nasal vault following rhinoplasty. Plast. Reconstr. Surg., 1984;73(2): 230-239.

16. Tastan, E., M. Demirci, E. Aydin, F. Aydogan, K. C. Kazikdas, M. Kurkcuoglu, et al. A novel method for internal nasal valve reconstruction: H-graft technique. Laryngoscope., 2011;121(3): 480-486.

17. Toriumi, D. M. Management of the middle nasal vault. Operat. Tech. Plast. Reconstr. Surg., 1995;2(1): 16-30.

18. Toriumi, D. M., J. Josen, M. Weinberger, M. E. Tardy, Jr. Use of alar batten grafts for correction of nasal valve collapse. Arch. Otolaryngol. Head Neck Surg., 1997;123(8): 802-808.

19. Yankov, D. V. Surgical treatment of the nasal osseo-cartilaginous vault deformities. PhD thesis. Varna, 2012, 112 p. (in Bulgarian). 